\title{
Agroecologia: paradigma para tempos futuros ou resistência para o tempo presente?*
}

\section{Agro-ecology: paradigm for the future or present-day resistance?}

\author{
Jalcione ALMEIDA*
}

\section{RESUMO}

Este é um ensaio que tenta "problematizar" a prática agroecológica, particularmente no que se refere ao seu potencial de transformar o social através de um movimento capaz de provocar alterações mais profundas nas formas de produção e de vida na agricultura e em sociedade. Além de apresentar e discutir seus limites, este trabalho também reflete sobre as potencialidades da agroecologia enquanto movimento social.

Palavras-chave: Agroecologia, movimentos sociais rurais, agir conflitual.

\begin{abstract}
This paper tries to render questions about the agroecological practice, particularly in what refers to its potential to transform the social through a movement capable of provoking deeper changes in production and life patterns in agriculture and in the society. Besides presenting and discussing its limitations, this paper also brings questions about the potentialities of agroecology as a social movement. Key-words: Agroecology, rural social movements, conflicting acting.
\end{abstract}

* Título parafraseado do artigo de J.-P. Garnier, “L'Écologisme: paradigme des temps futurs ou paravent pour le temps présent?", em L'Homme et Société (1994). Críticas e sugestões serão muito bem-vindas.

** Agrônomo, doutor em sociologia, professor e pesquisador do Programa de Pós-Graduação em Desenvolvimento Rural (PGDR) e da Faculdade de Agronomia, ambos da Universidade Federal do Rio Grande do Sul. Endereço para correspondência: PGDR/UFRGS - Avenida João Pessoa, 31 - $90.040-000$ Porto Alegre/RS. Fone/Fax: 0XX51-33163281.<jal@ufrgs.br> 
Este texto sintetiza alguns pontos de uma reflexão de longo termo sobre o tema das alternativas ao padrão tecnológico e do desenvolvimento rural na Região Sul do Brasil. Portanto, o que aqui é expresso tem muito a ver com a dinâmica social neste espaço geográfico. No que tange mais propriamente às políticas públicas agroecológicas, a referência é sempre o caso gaúcho.

\section{Breve introdução problematizadora}

A agroecologia surgiu como uma promessa de renovação do político, dos sistemas técnicos e como fonte de mudanças socioculturais. Passados alguns anos, o que ocorre com ela? Pode a agroecologia responder às crises social, econômica e ambiental simplesmente implementando alternativas de substituição ou de adaptação aos padrões técnico-produtivos convencionais que mostram seus limites e dão sinais de esgotamento? Deve se contentar em propor diferentes modos de inserção das atividades agrícolas e rurais familiares no tecido econômico e social local? Ou não se poderia da agroecologia esperar outra coisa em vista das idéias que defende e dos desejos e aspirações dos agentes sociais que a sustentam?

Este texto pretende responder, ainda que parcialmente, a essas questões, a partir da análise de experiências recentes no Rio Grande do Sul (de ONGs, de organismos governamentais e suas tentativas de implementação de políticas públicas) e da reflexão acadêmica de alguns anos sobre o tema, refletindo sobre a capacidade da agroecologia de provocar um agir conflitual, ${ }^{1}$ estimulando outras formas de agricultura, de convívio social e de desenvolvimento que promovam o abandono das tradicionais formas de reclusão identitária ou de adequação ao mercado assumidas pela maioria das atuais manifestações de contestação na agricultura e na sociedade.

Mais do que uma simples descrição das lutas e das reações sociais, o principal objetivo ao investigar-se este tema é o de refletir sobre as modificações que tais mani- festações de contestação e protesto engendram nas posições sociais, nas propriedades e atributos dos grupos e agentes em conflito e, em última análise, no espaço social. Em suma, este trabalho é uma tentativa de evidenciar os efeitos sociológicos das ações e lutas sociais em questão.

Os agentes e grupos sociais que questionam, em diferentes níveis, o padrão de desenvolvimento agrícola e rural, implementado a partir dos ideários da Revolução Verde, começaram a se constituir na metade da década de 1970. A luta pela terra, a resistência que opõe os pequenos agricultores familiares à construção de barragens hidrelétricas que os ameaçam de expropriação, as tentativas de implantação de novos assentamentos rurais em áreas conquistadas através da luta pela reforma agrária, as críticas e reivindicações concernentes às políticas agrícolas do Estado, a experimentação mais ou menos sistemática e organizada de "novas" tecnologias mais adaptadas às necessidades e à situação da pequena agricultura de caráter familiar, as reivindicações de maior cuidado com os recursos naturais não-renováveis, enfim, a luta ecologista e ambientalista, são algumas das orientações que embasam e ainda guiam o atual movimento de contestação (ALMEIDA, 1989; 1993;1989; ALMEIDA; NAVARRO, 1997). E é no interior desse grande movimento de contestação que subexistem e buscam se afirmar os agentes sociais e as ações coletivas que são objeto deste estudo.

A proposição agroecológica surgiu (e ainda se apresenta) como aspiração geral a uma outra forma de desenvolvimento. ${ }^{2}$ Ela tem-se apoiado no uso potencial da diversidade social e dos sistemas agrícolas, especialmente aqueles que os agentes reconhecem como estando o mais próximo dos "modelos" camponês e indígena. Aqueles que idealizam esse tipo de agricultura têm razões para pensar que, em se aliando a um projeto de desenvolvimento local, descentralizado, que privilegie a diversidade em cada meio, estão exprimindo novas aspirações, novas formas de sociabilidade, uma vontade em promover outros modos de desenvolvimento econômico e social que seriam mais "controláveis" e aceitos por-

1 A ação é o centro de criação de sentido. Não se pode, portanto, encontrar sentido fora da ação. Nessa perspectiva, ela surge como irredutível: decorre de uma emergência primária e radical e sua materialidade encontra-se no sentido, este sendo impensável antes da ação. Toda ação produz, por conseguinte, um sentido, e esse será novo, sobrepondo o antigo, quando decorrente de um agir conflitual. Nele, o agente se reconhece como (co)autor ou produtor de orientaçōes, situando-se no centro de uma trama de relações sociais que somente ganham sentido com a ação (ALMEIDA, 1999).

2 Não será feita aqui uma descrição exaustiva dos princípios e idéias agroecológicos. Para tanto, ver Almeiđa (1993; 1995), AS-PTA (1990), Altieri (1987; 1988), entre outros autores. 
que são espacialmente circunscritos, cultural e tecnicamente fundados na "experiência do tempo".

Ao mesmo tempo em que surgem e tentam afirmar novas noções, as ações e agentes agroecológicos visam a colocar em prática um novo tipo de movimento coletivo, que tenta fugir das formas mais ou menos reclusas que assume a maioria das manifestações de contestação da dominação social como um todo. Mas tal deslocamento de objetivos, mesmo que ainda de ordem estratégica $a^{3}$ e em estado embrionário, não poderia se dar sem grandes riscos. Uma vez mais, a atual condição de marginalização e exclusão de certos grupos sociais e a necessidade urgente em se obter "resultados imediatos" no plano da reprodução social constituem fatores que jogam contra a capacidade de contestação dessas novas idéias, pelo menos no curto e médio prazos. É por isso que essas formas de protesto muitas vezes são tendentes a se aproximar das esferas e padrões (normas) institucionais, assumindo um caráter ora de defesa identitária, ora de reintegração econômica no interior do mercado. Isso tem provocado o enfraquecimento de sua força contestadora e de grande parte de suas aspirações e utopias.

A grande heterogeneidade que ainda caracteriza a perspectiva agroecológica, particularmente em relação ao seu padrão tecnológico e suas formas sociais, tem-se constituído, por um lado, numa barreira ao avanço dessas idéias; por outro lado, este parece ser, paradoxalmente, o grande diferencial emulador do debate sobre os problemas da agricultura e a questão agrária no Brasil, ressaltando-se, muitas vezes, a sua contribuição para o tema/debate da agricultura familiar e da diversidade de formas de desenvolvimento.

Muitas das iniciativas recentes de grupos e organizações sociais, tanto no âmbito governamental (particularmente no caso do Rio Grande do Sul, há cerca de quatro anos) como não-governamental (experiências de ONGs, associações de agricultores, sindicatos, entre outros), têm-se concentrado na busca ou recuperação de alternativas tecnológicas aos sistemas produtivos "con- vencionais", tidos como esgotados, pois são considerados "poluentes", antieconômicos e incapazes de promover a autonomia dos agricultores familiares envolvidos.

A divulgação/generalização da proposição agroecológica parece, no entanto, encontrar alguma dificuldade. Suas aparentes virtudes teóricas e morais não foram ainda suficientes para alçá-la a um lugar de maior consideração e destaque no interior da agricultura e sociedade brasileiras. A "crise" que balançou com as estruturas do padrão de agricultura "convencional" parece não ter sido suficientemente forte para dar a essa posição um espaço e um impacto realmente importante e geral. ${ }^{4}$

Nesta perspectiva, a agroecologia se depara com as seguintes questões: como considerar/elevar a diversidade para além do protesto puro e simples?; como adaptá-la às ações de desenvolvimento que se dirigem tanto a uma clientela heterogênea quanto aos seus determinantes sociais, suas aptidões e meios materiais?; essas dificuldades não estariam ligadas a uma certa tendência ao isolamento, à prioridade dada a certas necessidades de camadas sociais que ainda não conseguiram despertar a atenção e o interesse do poder político instituído?

É no quadro delimitado por estas interrogações maiores que a reflexão será desenvolvida.

\section{Sobre a noção de agroecologia, a metodologia e a ação tecnológica}

A agroecologia é uma noção nova, freqüentemente sendo associada no debate social atual às noções de agricultura e desenvolvimento sustentáveis, tendo uma incidência em espaços geográficos e sociais bem circunscritos. No entanto, ainda que se tenha intensificado o debate em torno do tema, a agroecologia até agora foi superficialmente definida. Dependendo da posição social do "agente" que a define, têm-se compreensões

\footnotetext{
3 Tem-se aqui como referência o que propõe a Assessoria e Serviços em Projetos de Agricultura Alternativa (AS-PTA), ONG com sede no Rio de Janeiro que tenta articular uma rede brasileira de ONGs preocupadas com o tema da agroecologia e do desenvolvimento sustentável. No sul do Brasil, a Rede Tecnologias Alternativas/Sul (Rede TA/Sul) representa esta articulação, composta por 11 ONGs, dentre as quais o Centro de Tecnologias Alternativas Populares (Cetap), em Passo Fundo/RS; o Centro de Apoio ao Pequeno Agricultor (Capa), em São Lourenço do Sul/RS; o Centro Ecológico. em Ipê/RS; a Assesoar, em Francisco Beltrão; a Rureco, ambas no Paraná; o Vianei e a Apaco, em Santa Catarina.

4 Quando referida à agricultura "convencional", está subentendida a idéia geral de uma agricultura intensiva em capital, poupadora de mão-de-obra e fiel aos princípios técnicos consolidados pelo ideário da Revolução Verde, com as nuances regionais que o processo de "modernização da agricultura" conseguiu manifestar no Brasil.
} 
ou entendimentos diferentes a respeito: é uma atividade, uma prática, uma área do conhecimento (ciência agroecológica), ou tudo isso ao mesmo tempo? (ALMEIDA, 1999; COELHO, 2002). As posições assumidas neste debate têm-se restringido geralmente ao uso normativo e "ampliado" da noção, ou seja, através de grandes contornos de definição. No geral, incorporam idéias mais ambientais (ecológicas, preservacionistas/ conservacionistas do meio ambiente) e de sentimento social acerca da agricultura, o que implica um conjunto de "elementos" ou "componentes" sobre a sociedade e a produção agrícola que extrapola os limites do campo da agricultura. Esta amplitude da noção traz, às vezes, alguns problemas, na medida, por exemplo, em que confunde agroecologia ( $=$ instrumento técnico-científico) com desenvolvimento (= processo, política).

Neste sentido, é marcante o grau de abrangência das concepções, indo do "técnico-produtivo" à "construção de novas relações sociais entre os homens", passando pela "agricultura familiar" e pelo "desenvolvimento sustentável". Isso pode ser visto através de representações sociais da agroecologia significando:

1) a "busca de tecnologias de produção que não agridam o homem e o meio ambiente";

2) o "instrumento para criação de uma nova consciência social e ecológica";

3) uma "proposta mais coerente do ponto de vista da sustentabilidade e do desenvolvimento para o meio rural";

4) de fundamental importância "para se construir um processo novo de desenvolvimento no meio rural";

5) aquela "que compreende e dá conta das relações ecológicas que propiciam a reprodução das diferentes formas de vida existentes na natureza";

6) que "entende que as ações sociopolíticas podem contribuir para uma maior estabilidade e sustentabilidade dos agroecossistemas";

7) enfim, como uma "metodologia integradora que facilita o estudo e a intervenção na realidade dos agricultores, permitindo que a atividade agrícola seja analisada e avaliada na sua totalidade, onde emergem componentes bio lógicos, técnicos, culturais e socio-econômicos" (ALMEIDA, 1995).

Se, por um lado, tem-se a dificuldade de definir algo muito amplo, abrangente na noção em voga, por outro, tem-se também algumas limitações no sentido mais estrito, disciplinar, técnico-científico da agroecologia, quando, por exemplo, se faz referência ao "estudo de fenômenos puramente ecológicos que ocorrem nos campos dos cultivos agrícolas, tais como as relações predador/predado, ou a competição de cultivos e invasoras" (ALTIERI, 1987). Pouco se avançou, mesmo reconhecendo-se os esforços recentes através de iniciativas de algumas ONGs (como, por exemplo, o Centro Ecológico Ipê/RS) e de políticas públicas específicas, na direção de uma agroecologia voltada para a realidade local (o microssocial), com suas inúmeras especificidades e complexidade. $^{5}$

A agroecologia substituiu, pouco a pouco, a noção-chave (e reconhecidamente um pouco fragmentada) de "tecnologia alternativa", muito em voga no período de meados da década de 1970 até o final da década de 1980. Ela parece ampliar a percepção que se deve ter do agrícola, do rural e da sociedade. Mesmo sendo pensada primeiramente para tratar do "agro", a agroecologia, através de uma intervenção mais localizada, tem bem presente a visão macro, ou "sistêmica", ou até mesmo "planetária" (ver, por exemplo, as representações expressas anteriormente). $\mathrm{E}$, neste ponto, parece ter evoluído em relação à tecnologia (agricultura) alternativa.

No seu sentido mais estrito, como preconizam alguns autores "clássicos" sobre o tema (Miguel Altieri, Stephen Gliessman, Eduardo Sevilla Guzmán, entre outros), a agroecologia ainda não foi devidamente encarada e praticada. Constata-se, no entanto, que o uso da noção é "estratégico", pois sintetiza c mesno legitima as ações de muitos agentes, especialmente aquelas mais recentes.

Do ponto de vista metodológico, ainda não se conseguiu "operacionalizar" a noção de agroecologia. Esta compõe um sistema heterogêneo de intervenções, de variáveis, de elementos que precisam ser privilegiados a todo o momento. Não se consegue, dentro de um sistema de produção, intervir em todas as variáveis. Deve-se ter bem claro, então, que, ao interferir em uma variável,

5 Reside aqui também um outro problema "quebra-cabeça": como conectar o local com a pretensão política maior de afirmação da agroecologia como um movimento social? Pretende-se discutir um pouco sobre isso mais adiante. 
em um elemento ou mesmo na linha de produção (do "sistema de cultivo" ou "de criação"), ou em uma tecnologia qualquer dentro de um "sistema", se está interferindo no seu conjunto, e isso é algo muito importante a ser considerado.

Mesmo que ainda não se saiba muito bem como interferir nos "sistemas", pelo menos alguns agentes (individuais e coletivos) parecem demonstrar, do ponto de vista geral e discursivo, como se deve idealmente fazêlo. Falta, contudo, um maior domínio teórico e prático sobre o funcionamento desses "sistemas". A capacidade teórico-prática e a formação ao longo dos anos dos técnicos parecem ainda não ter sido adequadas e suficientes para atender a estas exigências. A estrutura de seu referencial teórico ainda não está montada; falta à agroecologia propor seus próprios paradigmas. Uma grande lacuna, portanto, é observada neste campo. A demora em responder a estes desafios teóricos e metodológicos pode consolidar a percepção de que a proposição agroecológica é incapaz de transformar seus princípios em ação. ${ }^{6}$

É forçoso reconhecer que a proposta agroecológica ainda é bem minoritária e incipiente no contexto social da produção agrícola brasileira, até mesmo marginalizada, mesmo reconhecendo-se que, em certas regiões, tem-se avançado consideravelmente na implementação de algumas políticas públicas (extensão e assistência técnica, pesquisa agrícola, recursos financeiros em programas específicos para a produção agroecológica, entre outras). A massificação/generalização desta proposta passa por várias questões que ainda não estão sendo trabalhadas, em espaços onde não se tem o poder suficiente para intervir. Mas, por menores ou ínfimas que sejam as intervenções atuais, deve-se ter a compreensão de que elas fazem parte de um processo educativo, de uma ação coletiva concertada necessária à construção de um processo mais amplo (voltar-se-á a esse ponto a seguir).

\section{Sobre a capacidade de generalização da proposta agroecológica}

A consolidação de um movimento social é condição sine qua non para a afirmação da proposta agroecológica. No entanto, se isso não basta, é necessário que se dê uma grande atenção a aspectos mais "domésticos" ou "menores" (quando comparados à tarefa de "criação" de um movimento social), mas também importantes. A reflexão acadêmica sobre o tema nos últimos anos tem evidenciado alguns limites ou problemas para a generalização da proposta no Sul do Brasil (ALMEIDA, 1995; 1998; 1999; SCHMITT et al. 1997; COELhO, 2002). É importante destacar que esses limites se interconectam, mantendo estreita relação entre si, muitas vezes um determinando o outro (e, ainda, ressalta-se, sua relação com a tarefa do movimento social). No geral, pode-se sintetizá-los da seguinte forma:

1) as resistências apresentadas devido ao caráter ideológico da intervenção técnica e social mais geral;

2) a falta de entrosamento (diálogo e intercâmbio) entre agentes sociais (individuais e coletivos) que atuam na mesma área, trabalham com os mesmos "objetos" e muitas vezes enfrentam os mesmos problemas;

3) o ainda pequeno e insuficiente acompanhamento de campo e sistematização das experiências agroecológicas, malgrado esforços recentes nesse sentido (por exemplo, Paulus et al., 2000, entre outros autores) $;^{7}$

4) os "gargalos" tecnológicos, ou seja, limites ou problemas ainda não bem solucionados na prática agroecológica de campo; e

5) a baixa capacitação profissional para enfrentamento da complexidade dos sistemas produtivos e da agroecologia.

6 A ânsia em intervir nos sistemas agrícolas de forma agroecológica tem, muitas vezes, consolidado, entre alguns agentes sociais, a idéia do "pacote agroecológico", desconhecendo-se ou minimizando-se a complexidade e diversidade dos sistemas produtivos, e tendendo-se a uniformizá-los para facilitar a ação tecnológica, a metodologia e a obtenção dos resultados. Claro está que este é um caminho equivocado, que, a exemplo do passado recente com os pacotes tecnológicos da agricultura "convencional", não deu certo, promovendo grandes desigualdades sociais e impactos ambientais.

7 Registre-se o marco referencial, em trabalhos deste tipo, aquele publicado pelo Programa de Cooperação em Agroecologia (PCA), que reunia várias ONGs no Sul do Brasil na década de 1990. 
Nos últimos 15 anos, experiência analítica em relação ao tema tem evidenciado uma "marca" muito característica da proposição agroecológica em contextos agrícolas e rurais no Sul do Brasil, particularmente no caso gaúcho: o marcado viés político-ideológico. Essa tendência, muito forte nos primórdios da agroecologia (ainda quando se falava em "agricultura alternativa", na década de 1970), arrefeceu-se um pouco em meados da década de 1990, readquirindo ímpeto, particularmente no caso gaúcho, ao final dessa década. No início, os agentes sociais promotores da agroecologia voltavam-se contra o Estado, pois nele reconheciam o principal "inimigo", ou seja, o grande emulador das tecnologias "modernas" ou "convencionais". Isso, associado ao preconceito ideológico e a um ufanismo inicial mais ou menos generalizado entre os agentes agroecológicos, talvez tenham sido as principais causas do isolamento (ou do tímido resultado no trabalho de irradiação) dessas propostas. Esses agentes, portanto, não (ou mal) se relacionavam com os órgãos estatais, algumas ONGS, por exemplo, tendo chegado a se recusar a trabalhar com os serviços de extensão rural e assistência técnica oficiais.

O período das proposições tecnológicas alternativas (TAs), de 1970 ao final da década de 1980, foi aquele em que a oposição "alternativo" x "moderno" ou "oficial" foi mais forte. Daí originou-se um dos grandes equívocos da proposta de TAs que foi o de "bancar" um "modelo alternativo" sem bases epistemológicas e políticas verdadeiras, em cima apenas da crítica e da oposição pouco consequiente ao "modelo" agrícola "moderno" vigente. Foi o período em que a crítica contracultural foi a tônica, centrada em um discurso contra a sociedade industrial e seus processos (ALMEIDA, 1989).

No início da década de 1990 , ocorreu uma certa aproximação entre alguns agentes governamentais e nãogovernamentais (por exemplo, como caso mais emblemático, o relacionamento da ONG Centro de Tecnologias Alternativas Populares - Cetap e a Empresa Brasileira de Pesquisa Agropecuária - Embrapa, em Passo Fundo/RS). Com a chegada, no final dessa década, no Rio Grande do Sul de um governo identificado com essas propostas agroecológicas, estas passaram gradualmente a embasar algumas políticas públicas.

A origem e trajetória política e social nos últimos 20 anos dos principais agentes agroecológicos em atividade forjaram um discurso e uma ação coerente com esses princípios contestadores da "sociedade industrial", influenciados também por segmentos "progressistas" da Igreja Católica e pelos partidos de esquerda, politicamente bastante atuantes neste período. Isso leva à hipótese de existência de um "vínculo genético" que explicaria a forte marca ideológica até hoje no "movimento" agroecológico.

Mas essa histórica e explícita vinculação com o campo político-ideológico trouxeram problemas de relacionamento e de afirmação para a proposição agroecológica, na medida em que a tentativa de universalização parece ter sido prejudicada, pois foi identificada com um ideário político partidário ou com grupos políticos específicos. Até mesmo o entrosamento e a estreita relação a serem estabelecidos entre os agentes agroecológicos foram ao longo do tempo afetados, na medida em que persistiram algumas "diferenças" de caráter político mais geral e, por conseguinte, de condução das principais ações e iniciativas no seio dos grupos agroecológicos. ${ }^{8}$

Já em relação à capacitação dos agentes agroecológicos, esta ainda se mostra deficiente de maneira geral. Pela dificuldade de penetração nos espaços acadêmicos mais consolidados, a proposta fica se reciclando entre um número reduzido e permanente de técnicos reconhecidos por sua alta contribuição ao tema. A intensificação e diversificação desta capacitação dos agentes certamente deverão permitir uma inter enção mais qualificada a campo, servindo-se das sisteı natizações que as diferentes equipes deverão realizar, aportando, assim, elementos de conhecimento para atender aos desafios tecnológicos crescentes. Em virtude da pouca sistematização das experiências até agora, fica bastante prejudicada a aferição dos impactos das tecnologias e práticas agroecológicas preconizadas. A avaliação/constatação empírica das poucas experiências não permite uma verificação fidedigna. ${ }^{9}$

\footnotetext{
8 Alguns eventos recentes parecem mostrar uma certa fissura entre esses agentes, cristalizando diferenças que dizem respeito à metodologia, aos beneficiários prioritários e aos espaços a serem abertos e consolidados pela ação agroecológica. Isto pode ser bem visualizado através dos princípios e formas de organização de dois grandes eventos agroecológicos: o Encontro Nacional de Agroecologia, realizado em julho de 2002, no Rio de Janeiro, e os seminários sobre agroecologia promovidos pela Emater-RS nos últimos três anos, em Porto Alegre-RS.

9 É louvável, no entanto, o trabalho da Emater-RS nos últimos quatro anos, no sentido da capacitação de seus quadros, em diferentes níveis (aperfeiçoamento, especialização, mestrado e doutorado), bem como as diferentes publicações tentando sistematizar experiências agroecológicas no Rio Grande do Sul.
} 
Quanto aos "gargalos" tecnológicos, estes ocorrem freqüentemente em dois níveis: nas tecnologias em si, através de um problema de ordem metodológica, ou seja, na dificuldade que se tem em inserir essas novas tecnologias nos sistemas produtivos (aspecto já mencionado e discutido anteriormente), e, em outro plano, nos sistemas produtivos ou agroecossistemas, ou seja, na dificuldade mais ou menos generalizada de aprofundamento do conhecimento sobre os "sistemas" agrícolas (faita de clareza a respeito de suas dinâmicas).

Das diversas "tecnologias agroecológicas" preconizadas, algumas delas apresentam dificuldades para sua real implementação até mesmo em contextos microrregionais ou locais. A utilização de leguminosas para adubação verde associada à prática do plantio direto, por exemplo, funciona em determinada região, mas não muito bem em outra, em situações não muito distantes entre si. Isso sem falar da falta de proposições mais consistentes e duradouras no que tange às alternativas de mercado, em que faltam tecnologias para viabilizar determinados sistemas de produção propostos; no "problema" do controle de ervas daninhas; na substituição de agrotóxicos; na intensificação da mão-de-obra no interior das unidades de produção; os constantes desafios do plantio direto; a reestruturação das práticas agrícolas "convencionais", entre outros aspectos determinantes.

Menciona-se, en passant, porém não lhe diminuindo a importância, um outro problema que é a falta de uma melhor compreensão técnico-científica dos princípios agroecológicos por parte dos técnicos e agricultores, o que tem levado também a uma certa lentidão na detecção de problemas no âmbito dos sistemas de produção. $\mathrm{O}$ ainda baixo nível de conhecimento técnico sobre as propostas ou tecnologias agroecológicas leva frequientemente à repetição de argumentos genéricos e/ou generalizantes, reforçando chavões que são largamente reproduzidos tanto no debate social mais geral como no meio acadêmico. Uma maior e melhor qualificação técnica neste tema poderia, também, reforçar os argumentos e idéias no debate dentro do campo científico.

A maior incidência no campo científico da proposição agroecológica poderá surtir efeitos no médio prazo no sentido da "reformatação" da pesquisa agronômi- ca, retirando-lhe aquele viés tradicional que tende a particularizar as rotinas de investigação e métodos para a produção do conhecimento, que leva a recortar a realidade segundo processos básicos formativos de seu campo específico de trabalho. Confrontada a outras realidades, a pesquisa clássica poderia produzir melhores resultados, desde que fosse operada "por demanda" $10 \mathrm{e}$ não mais a partir de uma oferta nascida apenas de estratégias das agências fomentadoras da pesquisa nas instituições tradicionais de experimentação, estas muitas vezes distanciadas das realidades do "mundo rural". Alguns exemplos recentes nesse sentido, ainda que não através de princípios agroecológicos estritos, mas de forte caráter ambiental e conservacionista, nos estados do Paraná e Santa Catarina, estimulados por programas públicos estatais, mostram que é possível se pensar em algo diferente, metodologicamente novo em se tratando da pesquisa agrícola, da assistência técnica e da extensão rural (NAVARRO, 1999). ${ }^{11}$

$O$ investimento na sistematização e no melhoramento das experiências, associado a um maior e mais efetivo contato com entidades de pesquisa (governamentais ou não), poderão abrir alguns novos caminhos para a resolução de determinados problemas tecnológicos. A abertura de certas entidades governamentais, notada nos últimos tempos, ligada à determinação dos agentes agroecológicos em disputar "objetos" (e objetivos) tecnológicos no campo científico, contribuirá certamente para um relacionamento mais profícuo nesta área.

Nesta perspectiva, diante de tudo que foi até aqui exposto, pode-se referir que o equacionamento da dualidade entre o "técnico" e o "político" no discurso e na prática agroecológica, dimensões essas muito debatidas no âmbito deste trabalho, precisa ser encarado de frente para clarificar a própria tarefa institucional de cada agente e mesmo as prioridades de trabalho. ${ }^{12}$ No mesmo sentido, é necessário esclarecer melhor a compreensão das tradicionais "ferramentas" de trabalho agroecológico, como a experimentação, demonstração, formação, capacitação, assessoria e acompanhamento. Essas tentativas têm-se confundido ou, às vezes, até mesmo se complementado, nas ações. Se identificadas mais precisamente, poder-se-iam traçar metas e mesmo delimitar responsabilidades de forma mais explícita.

10 Aqui se ressalta a importância de um movimento social capaz de "criar a demanda" agroecológica (ver item a seguir).

11 Este autor faz referência específica aos programas "Paraná Rural" e "Microbacias", em Santa Catarina (NAVARRO, 1999).

12 A falta de uma melhor compreensão da relação entre o político e o fécnico fica bem expressa na seguinte manifestação: “.... pois a agroecologia não é |umal proposta política, mas sim uma proposta de solução para a crise da agricultura que estamos iniciando a enfrentar, e que aqui [no Rio Grande do Sul] ainda está longe de demonstrar o quanto prejudicial o modelo convencional é" (manifestaçāo a este autor de um professor e pesquisador da UFRGS, em fevereiro de 2002). 


\section{Resposta à crise ou movimento social? Protesto ou projeto social? Alternativa de mercado ou agir conflitual?}

Constata-se, entretanto, que, apesar de suas debilidades, a proposição agroecológica, reforçando a diversidade da base social e produtiva dos "modelos" que se implantam, já impôs em certos contextos sociais limites ao desenvolvimento que prega o Estado e as classes dirigentes, estes influenciados que são por grandes interesses privados econômicos e políticos mundiais. Sua influência vai também na direção do encorajamento de modos de desenvolvimento agrícola e rural pouco hierarquizados, que escapem da forte influência estatal e de seus organismos sobre o "social". Pelo menos, a proposição agroecológica é capaz de servir eficazmente como instrumento de resistência e de reprodução de grupos sociais no respeito de sua diversidade.

Pode-se, portanto, neste momento, retomar o questionamento anunciado no início deste ensaio: tem a agroecologia o papel de responder à crise (ou resistir a ela), simplesmente implementando alternativas de substituição ou de adaptação aos padrões técnico-produtivos que mostram seus limites e dão sinais de esgotamento? Deve-se contentar em propor diferentes modos de inserção das explorações familiares no tecido econômico e social local? Ou não se poderia dela esperar outra coisa em vista das idéias que defende e dos desejos e aspirações de certos agentes? Formulando-se a questão de outra maneira, se poderia perguntar: a agroecologia é uma nova ciência, uma nova proposta (política) de desenvolvimento agrícola e rural, um novo movimento social ou uma alternativa técnico-produtiva de superação dos gargalos tecnológicos da agricultura "convencional"?

A agroecologia (e por extensão, em um certo sentido, o que até alguns anos atrás se chamou de agricultura "alternativa") não constitui ainda o que se poderia chamar um movimento social stricto sensu, ou seja, uma ação social organizada contra o poder de adversários que têm as rédeas do modo de desenvolvimento agríco- la. A luta agroecológica poderá provocar uma autêntica e profunda transformação no campo político (ela propõe desde já, concretamente, uma mutação no domínio técnico-produtivo e nas práticas agrícolas através de princípios que se ligam a um paradigma ecológico), desde que saiba "costurar" as alianças capazes de provocar uma ampliação de seu poder de luta. ${ }^{13}$ Essas lutas deverão se encaminhar na direção da convergência (e da complementaridade) com outras formas de combate e de movimentos sociais, a fim de fazer desta ação a precursora por excelência de um movimento social mais amplo e dirigido contra a tecnocracia que dita as necessidades de uma população a qual domina. Por enquanto, a agroecologia é a expressão de iniciativas de grupos ou agentes sociais mais ou menos isolados, com resultados técnicos e sociais em diferentes amplitudes, agentes estes que poderão vir a integrar um movimento social, mas que atualmente não constituem e não representam um movimento social.

Em suma, é necessário que as proposições agroecológicas, se quiserem abrir a via para um movimento social, transcendam a lógica contestadora dominante que visa a exercer uma pressão puramente institucional e isolada. ${ }^{14}$ Para isso, a agroecologia poderá utilizar a ecologia e sua problemática de uma maneira transversal, dentro de contextos, como diz Guattari (1989), "de desintegração, de multiplicação de antagonismos e de processos de singularização". Assim, a contestação cultural ou puramente econômica poderá se transformar em um movimento de ação propriamente sociopolítico. Este objetivo parece ainda não ter sido atingido.

Os acontecimentos mais recentes (1999-2002) no estado do Rio Grande do Sul, estimulados pela vontade política do governo em transformar a agroecologia em política pública e eixo condutor da agricultura gaúcha, foram, no entanto, frequientemente desviados para um debate ideológico, que parece ter criado mais inimigos e opositores à agroecologia do que aliados, ainda que tenha reforçado as posições políticas e técnicas no cerne dirigente do governo gaúcho. ${ }^{15}$ Mesmo reconhecendo a grande visibilidade que a agroecologia ganhou no Sul

13 Campo, aqui, é entendido na concepção de Pierre Bourdieu, como um espaço de lutas, um campo de relações objetivas entre indivíduos ou instituições que competem por um mesmo objeto.

14 Entretanto, não se pode fazer uma total abstração disso, visto que um movimento social é feito também de pressões políticas institucionais.

15 Destaca-se também neste período uma tendência bem visível de normatização da agroecologia, tentando definir os contornos desta nova prática (ou ciência?) agrícola. Esta iniciativa trouxe alguns problemas quando foi confundida, por vezes, com a tentativa de implantação de um novo pacote tecnológico, "um negativo do pacote tecnológico da Revolução Verde", como afirmam alguns técnicos, além do que se mostrou difícil de efetivar-se devido às várias compreensões/definições, até mesmo no interior dos organismos públicos oficiais, de agroecologia. 
do Brasil, particularmente no Rio Grande do Sul, pode-se ainda questionar a sua penetração nos diferentes níveis da sociedade, particularmente no campo científico e nos espaços sociais agrários mais amplos.

A dificuldade de afirmação das idéias agroecológicas, que ainda carecem de experimentação em "grande escala", com melhor e maior sistematização e análise dos resultados, é também devida à grande resistência que os agentes representantes ou defensores das tecnologias "modernas" ou "convencionais" impõem aos seus oponentes no campo científico. A crise tão propalada do paradigma científico "moderno" ainda não atingiu níveis que pudessem quebrar a sua monoliticidade e, portanto, as posições divergentes são vistas como menos importantes, por vezes até mesmo inadequadas cientificamente (COELHO, 2002; ALMEIDA, 1998; 1999). A verdade única do paradigma dominante, portanto, ainda prevalece.

O campo científico tem costumeiramente incidido em um ponto de crítica, aquele da falta de cientificidade ou de legitimidade científica da agroecologia, tendendo a desqualificar as iniciativas e as proposições agroecológicas, impingindo-lhes o rótulo de "tecno-logias retrógradas" e/ou "anticientíficas". Concordando ou não com essa crítica, pode-se imaginar que a dimensão de "novidade"16 desta proposição - paradigmática, talvez -, será função da capacidade que mostrarão as lutas agroecológicas para escapar não somente da lógica de ação puramente contestadora, mas também da institucionalização, do enclausuramento no interior de espaços morais e socioculturais específicos e, ainda, mostrar uma capacidade renovada para abrir novas vias de afirmação no domínio das maneiras de produzir e de viver. Esta proposta, enquanto projeto político, passa necessariamente por sua afirmação como "nova ciência", a qual desde já se propõe. É, portanto, também no espaço social configurado pelo campo científico que essas proposições devem-se afirmar. Para isso, devem disputar "objetos científicos" (ALMEIDA, 1998), buscando legitimidade científica capaz de subsidiar/sustentar a luta no campo político e social mais amplo, incorporando (e fazendo incorporar) conceitos, valores e técnicas capazes de serem compartilhados por determinada comunidade científica e utilizados para definir problemas e soluções. Não é, pois, simplesmente negando a "velha ciência" e recusando-se ao jogo político no campo científico que a agroecologia chegará a se afirmar/generalizar. ${ }^{17}$

\section{Ousando construir cenários para o futuro}

No atual contexto sociopolítico do Sul do Brasil, coerentemente com o que foi até aqui exposto, a agroecologia parece indicar três cenários possíveis de concretização, três etapas de desenvolvimento identifi-cáveis no plano analítico, a saber: uma, concebida como sendo a institucionalização da marginalização da agricultura alternativa ou ecológica; uma segunda, que corresponde a uma certa "ecologização" da agricultura moderna ou convencional; e uma última, em que a agricultura ecológica poderá ser apreendida enquanto uma verdadeira alternativa técnico-científica global.

A curto termo, as proposições agroecológicas podem ser bem apreendidas por um certo tipo de agricultores, de pequeno porte e de cunho familiar, "em dificuldade", situado em regiões onde faltam recursos materiais, físicos e financeiros, e produzindo antes de tudo para assegurar sua subsistência. A médio e longo prazos, o segundo cenário aparece de forma muito plausível. De fato, em se tratando de uma agricultura convencional de maneira específica e de sua "ecologização", certos fatos já se manifestam de forma visível através de práticas mais voltadas para a conservação ambiental, como, por exemplo, o uso da compostagem, da adubação verde, enfim, do manejo ecológico dos solos, do recurso à luta biológica integrada contra pragas e doenças, bem como nos programas "oficiais" de agricultura sustentável,$^{18}$ o que implica o aban-

16 Conforme a noção consagrada por Morin (1977). O novo, na maioria das experiências agroecológicas no Sul do Brasil, reside muito mais na forma de trabalho, que valoriza os processos de conhecimento estabelecidos entre os agricultores, no caráter educativo da relação técnico-agricultor e na valorização do "saber camponês ou indígena". Portanto, se o novo existe, ele está mais relacionado à forma - e à maneira (política) de sua vinculação - que ao conteúdo técnico das proposições (SCHMITT; DAMBORIARENA; ALMEIDA; NAVARRO, 1997; ABRAMOVAY; MIRANDA, 1996; 1997).

17 Ao invés de uma "aliança agroecológica" para enfrentar a luta no campo científico, nota-se hoje no Sul do Brasil um acirramento na disputa entre posições de alguns pesquisadores favoráveis à agroecologia na Academia e agentes sociais nas ONGs agroecológicas, estes disputando a definição do que seja a agroecologia e a legitimidade de falar em seu nome (COELHO, 2002), como se essas não fossem as duas faces de uma mesma moeda. Para uma discussão mais aprofundada sobre a disputa das tecnologias "alternativas" no campo científico, a questão da sua validação e da sua capacidade de generalização, ver Almeida (1998).

18 Por exemplo, os diversos programas da Embrapa. 
dono de certos produtos e práticas consideradas como altamente nocivas para o homem e o meio ambiente. ${ }^{19}$

No que se refere ao cenário prospectivo de apreensão da agricultura ecológica como alternativa técnico-produtiva global, parece que a construção deste novo paradigma, a menos que se realize uma boa parte das condições sociais e políticas esboçadas anteriormente para a agroecologia brasileira, enfrentará sérias dificuldades para se afirmar enquanto um processo realmente transformador. O cenário no horizonte próximo é aquele da agroecologia interiorizada no plano societal, não afetando fundamentalmente a estrutura da(s) agricultura(s) e sociedade(s).

\section{Considerações finais}

Tem-se, no entanto, que reconhecer que essas ações/manifestações no campo da agroecologia se inserem no quadro de uma renovação - mesmo que passageira - do político e do sistema técnico-produtivo, podendo constituir-se em fontes de mudanças culturais. Essas ações, porém, ainda não conseguiram investir com força no agir de tipo conflitual propriamente dito.

Por mais minoritárias que sejam essas ações e esses agentes no contexto do amplo movimento de contestação ao "modelo" de desenvolvimento vigente, parecem indicar uma outra direção, pensando a "problemática" da agricultura e de alguns aspectos da sociedade em termos suscetíveis de provocar um transbordamento dos espaços sociais constituídos, mesmo que, por enquanto, denotem características ainda um pouco fluidas, às vezes ambíguas e mesmo contraditórias, muitas vezes circunscritas à exaltação ideológica e/ou moral de seus pressupostos, dos pretensos benefícios e de sua superioridade em relação às outras "ciências". Essas ações começam, assim, sob a coordenação de certos agentes específicos, a buscar outras "interpretações" sociais que possam indicar uma possibilidade de operar um (novo) sentido para o social. Seu sucesso reside na capacidade de lutar e afirmar seu potencial político transformador, agregando diferentes categorias e grupos sociais, mobilizando-os no sentido da sua afirmação enquanto alternativa sociopolítica capaz de superar os impasses do atual padrão de desenvolvimento. Nesta linha de raciocínio, são fundamentalmente razões sociais e políticas aquelas capazes de afirmar verdadeiros movimentos sociais, amplificados, e não necessariamente os méritos técnicos e morais do conjunto de idéias ou proposições em questão.

No entanto, a proposição e a estratégia agroecológicas são ainda frágeis. Por um lado, fundam-se em critérios fortemente culturais e técnico-econômicos e muito pouco em critérios sociopolíticos, que levam, através de um encantamento por vezes moralista e acrítico, a distinguir e privilegiar as agriculturas "camponesas" ou "indígenas". ${ }^{20}$ Por outro, quando tratadas sob o ângulo sociopolítico, geralmente entram no plano da confrontação ideológica, tendente a valorizar sobremaneira os princípios morais e técnicos da agroecologia, que mais divide do que unifica a luta em torno de sua afirmação/generalização. As ideologias oficiais no plano da agroecologia geralmente têm-se mantido no plano das generalidades, pouco investindo na operacio-nalidade e em atividades específicas, tendentes a criar um discurso generalizante, de sentido único, tentando agregar pessoas em torno dele, com isso criando polaridades políticas contra a "agricultura moderna". Enquanto isso, os agentes técnicos que se situam na outra ponta do processo, aqueles mais envolvidos com as experiências e a adoção de tecnologias agroecológicas por parte dos agricultores, se referem genericamente à agroecologia como um "conjunto de técnicas produtivas", estas se aproximando de uma idéia ainda superficial do que sejam os "cultivos ecologicamente implementados", como, por exemplo, menor uso possível de insumos agroindustriais, maior proteção do solo, combinação de cultivos, ampliação da biodiversidade etc. Em resumo, existe um grande vácuo atual entre um discurso agroecológico de caráter fortemente ideológico, que tenta implementar políticas públicas, como é o caso no Rio Grande do Sul, e a prática

19 No geral, o que tem sido proposto como agroecológico até agoraé mais identificadoà etapa de desenvolvimento da agricultura em que predominavam os sistemas produtivos sem pousio e intensivos em mão-de-obra, com forte adubação orgânica e muita diversidade de cultivos e atividades (policultura), viabilizados pela introdução e uso de certas leguminosas nas rotações. Esta etapa do desenvolvimento, segundo Veiga (1991), baseada em processos e manejos específicos de uso dos solos, é característica de um período anterior à Revolução Industrial.

20 Este encantamento pode ser percebido entre os agentes do "movimento", das forças políticas que o apóiam e até mesmo nos meios acadêmicos, sempre de uma forma pouco crítica e deficiente do ponto de vista analítico. Nos dois primeiros âmbitos, isso pode não ser surpreendente, mas no meio acadêmico o é. Neste sentido, parece emblemático o artigo de Costa Neto $(1999 ; 2000)$. 
"agroecológica" real, que mais se aproxima de uma agricultura poupadora de insumos e menos impactante do meio ambiente, em nada se distinguindo das múltiplas versões de "agricultura sustentável" muito em voga nos meios oficiais e não-governamentais pelo mundo afora.

Por ora, a agroecologia está longe de adquirir a força do modelo que ela pretende substituir. Baseandose em identidades culturais e práticas produtivas que recusam antes de tudo serem qualificadas de "modernas", corre o risco de ficar à margem na discussão de novas alternativas ao padrão dominante de desenvolvimento. Este, mesmo estando atualmente em crise, fragilizado e alvo de severas críticas, possui ainda uma grande capacidade de recuperação, aliás, como já pôde demonstrar em diversas ocasiões. A discussão em torno da sustentabilidade da agricultura, fora do "espaço agroecológico", em uma arena política que envolve agentes sociais bem diferenciados entre organismos governamentais e não-governamentais pelo mundo afora, inclusive a discussão mundial em torno da melhor adaptabilidade dos novos padrões biotecnológicos a essas exigências de sustentabilidade, parece muitas vezes ignorar os pressupostos, as estratégias e experiências agroecológicas praticadas.

A proposição agroecológica, além dos desafios tecnológicos e metodológicos colocados a sua frente, deve ser capaz de promover a autonomia política dos agricultores, ${ }^{21}$ livrando-os da dependência do Estado, da guetificação sociocultural e do simples enquadramento às regras do mercado. Taticamente, o momento é de se trabalhar a transição para uma agricultura "di-

\section{REFERÊNCIAS}

ABRAMOVAY, R.; MIRANDA, C. R. Avaliação do Centro Vianei de Educação Popular. Lages, julho de 1996. Documento de uso restrito. Mimeog.

__. Avaliação da Associação dos Pequenos Agricultores do Oeste Catarinense (APACO). Chapecó/São Paulo/ Concórdia, junho de 1997. Documento de uso restrito. Mimeog. ferente", mais sustentável do ponto de vista ambiental e social (ALMEIDA, 1999); estrategicamente, no médio e longo prazos, é pensar na consolidação de um verdadeiro movimento social. Os agentes e forças sociais envolvidos diretamente com a agroecologia deverão se mostrar capazes desta árdua tarefa, sob pena de não viabilizá-la socialmente.

Eis a hercúlea tarefa com que se defronta a agroecologia, em um espaço onde se desenvolve uma intensa crise social e econômica. Estes desafios, que por instante tomam a forma de um ideal estratégico, ainda mal definido nas ações e lutas em curso, devem construir um projeto social capaz de orientar a sociedade, de introduzir um novo quadro de conceitualização social; um projeto que ultrapasse o campo da contestação e da oposição pura e simples à tecnocracia, ao produtivismo e às políticas agrícolas inadequadas; um projeto, enfim, que ande na direção de um modo propriamente conflitual, substituindo no coração da contestação os verdadeiros aspectos e instrumentos da dominação social no seu conjunto. Tais ações deverão mostrar mais claramente que se pode reconstruir uma imagem da trama social a partir da agregação de indivíduos e de grupos que parecem ter perdido hoje toda forma de identificação profissional e social; precisará subverter os antigos sinais de reconhecimento social a fim de construir um outro tipo de unidade. Não será, pois, somente com as tentativas de inserção/viabilização econômica, através de novas tecnologias e novos e alternativos canais de comercialização dentro da globalização avassaladora, que a agroecologia irá se impor política e socialmente.
ALMEIDA, J. Tecnologia "moderna" versus tecnologia "alternativa": a luta pelo monopólio da competência tecnológica na agricultura. Porto Alegre, 1989. Dissertação (Mestrado) Programa de Pós-Graduação em Sociologia Rural - Universidade Federal do Rio Grande do Sul.

Significados sociais da agroecologia e do desenvolvimento sustentável no espaço agrícola e rural do Sul do Brasil.

21 Para a noção de autonomia política e suas implicações (inclusive a do projeto político), ver Almeida (1999). 
Porto Alegre: Programa de Pós-Graduação em Sociologia/ UFRGS, set. 1995. Relatório CNPq.

; NAVARRO, Z. Reconstruindo a agricultura: idéias e ideais na perspectiva do desenvolvimento rural sustentável. Porto Alegre: UFRGS, 1997.

Tecnologias agrícolas "alternativas": nascimento de um novo paradigma? Ensaios FEE, Porto Alegre, v. 19, n. 2, p. $116-131,1998$.

A construção social de uma nova agricultura. Porto Alegre: UFRGS, 1999.

ALTIERI, M. Agroecology: the scientific basis of alternative agriculture. Boulder: Westview Press, 1987.

Potencialidades da agroecologia para o desenvolvimento da América Latina. Rio de Janeiro: PTA/FASE, documento 16, 1988.

ASSESSORIA e Serviços a Projetos em Agricultura Alternati$v a$. Estratégia e natureza da AS-PTA. Rio de Janeiro: AS-PTA, 1990. Datilografado.

COELHO, V. P. Mediadores técnicos, tecnociência na agricultura e a definição le gítima da problemática ambiental no campo tecnocientífico. Porto Alegre, 2002. Dissertação (Mestrado) - Programa de Pós-Graduação em Desenvolvimento Rural (PGDR).

COSTA NETO, C. Reforma agrária agroecológica em assentamentos rurais sustentáveis: uma visão comparativa. Revista da
$A B R A$, v. 29, n. 3 , set./dez. 1999 e v. 30 , n. 1-3, p. $87-100$, jan./ dez. 2000.

FLORES, M. X. et al. Pesquisa para agricultura auto-sustentada. Revista da Sober, Brasília, v. 29, n. 1, p. 1-21, jan./mar. 1991.

GLIESSMAN, S. R. Agroecologia: processos ecológicos em agricultura sustentável. Porto Alegre: UFRGS, 2000.

GUATTARI, F. Les trois écologies. Paris: Galilée, 1989.

JOLLIVET, M. (Dir.). Pour une agriculture diversifiée. Paris: L'Harmattan, 1988.

MORIN, E. La méthode, 1: la nature de la nature. Paris: Seuil/ Essais, 1977.

NAVARRO, Z. Manejo de recursos naturais e desenvolvimento rural: um estudo comparativo em quatro estados brasileiros. Porto Alegre, 1999. Relatório final, versão preliminar. Mimeog.

PAULUS, G.; MULlER, A. M.; BARCELlOS, L. A. R. (Coord.). Agroecologia aplicada: práticas e métodos para uma agricultura de base ecológica. Porto Alegre: Emater-RS/ PróGuaíba, dez. 2000.

SCHMITT, C. et al. Relatório de avaliação do CETAP - 10 anos. Porto Alegre, fev. 1997. Documento de uso restrito. Mimeog.

VEIGA, J. E. O desenvolvimento agrícola: uma visão histórica. São Paulo: Edusp/Hucitec, 1991. 